\section{Structure of interleukin 16 resembles a PDZ domain with an occluded peptide binding site}

The structure of a folded core of IL-16 is similar to that of intracellular protein modules called PDZ domains. IL-16 is thus the first extracellular protein found to have a PDZ-like fold. However, it does not exhibit normal peptide binding properties of PDZ domains. This is due to alterations of the structure at the 'PDZ-like binding site' of IL-16 (the GLGF cleft): the GLGF cleft of IL-16 is much smaller than those of PDZ-domains and is additionally blocked with a tryptophan side chain at its center. 0 ur experiments indicate al so that IL16 nonspecifically aggregates in solution; but formation of a homo-tetrameric protein is not required, in contrast to previous suggestions, for its chemo-attractant activity.

Interleukin 16 (IL-16), initially termed lymphocyte chemoattractant factor (LCF), is a pleiotropic pro-inflammatory cytokine1,2. Recently, Baier et al. showed that recombinant human IL-16 inhibits replication of human immunodeficiency viruses in primary cells $s^{3}$. The bioactive IL-16 is constitutively synthesized and stored in CD8+ ${ }^{+}$cells. It is also found in human leukemic, bone marrow-cultured and lung mast cells $s^{4}$. Additionally, the target cells themselves, for example, the CD 4 ${ }^{+} \mathrm{T}$ cells, are capable of storing a precursor IL-16 but contain no preformed bioactive protein. Activation of $\mathrm{CD}^{+} \mathrm{T}$ cells by I L-16 is correlated with induction of the expression of the IL-2 receptor, upregulation of the major histocompability complex ( $\mathrm{M} \mathrm{HC}$ ) class II and increases of the intracellular $\mathrm{Ca}^{2+}$ and inositol-1,4,5-triphosphate fluxes in CD 4+ $T$ cells ${ }^{5}$. The dependence of IL-16 activity on the level of CD 4 expression at the cell surface implies that CD4 is the target signal transducing receptor for IL-16. The activation of the CD $4^{+} T$ cells leads to their progression from the resting $G_{0}$ phase to the $G_{1 a}$ phase of the cell cyclé.

The most recently discussed role for IL-16 has been its function as a CD 8+ T cell- derived human immunodeficiency virus (HIV )-suppressive factor ${ }^{7-9}$. Baier et al. detected an inhibitory activity of IL-16 for the replication of human immunodeficiency viruses in primary cells ${ }^{3}$. Levy et al. in their experiments, however, could only observe the recombinant IL-16 HIV-suppressive activity at very high concentrations, much higher than those of other CD $8^{+} \mathrm{T}$-cell-derived antiviral factors, like, for example, the $\beta$-chemokines RANTES, MIP- $1 \alpha$ and MIP- $1 \beta^{10}$. It has been shown that human CD $4^{+}$cells transfected with IL-16-cDNA are resistant to HIV-1 infection, thus suggesting that IL-16 inhibits mRNA transcription of viral HIV-1 DNA ${ }^{11,12}$. There is also evidence that an IL-16 mediated signaling pathway represses the H IV-1 promoter activity, especially by overriding the effect of the HIV-1 activators NF- $\kappa B$ and Tat $^{13}$. Thus, there is ample evidence for the involvement of IL-16 in HIV suppression, although at this stagethe mechanism and function of IL-16 in HIV suppression are not understood.

Here we report structural NMR and functional studies of a processed IL-16 and several shorter fragments. The human IL-16 CDNA cloned initially for this work encodes a 130 amino acid protein ${ }^{14}$ that was suggested to be a secreted single
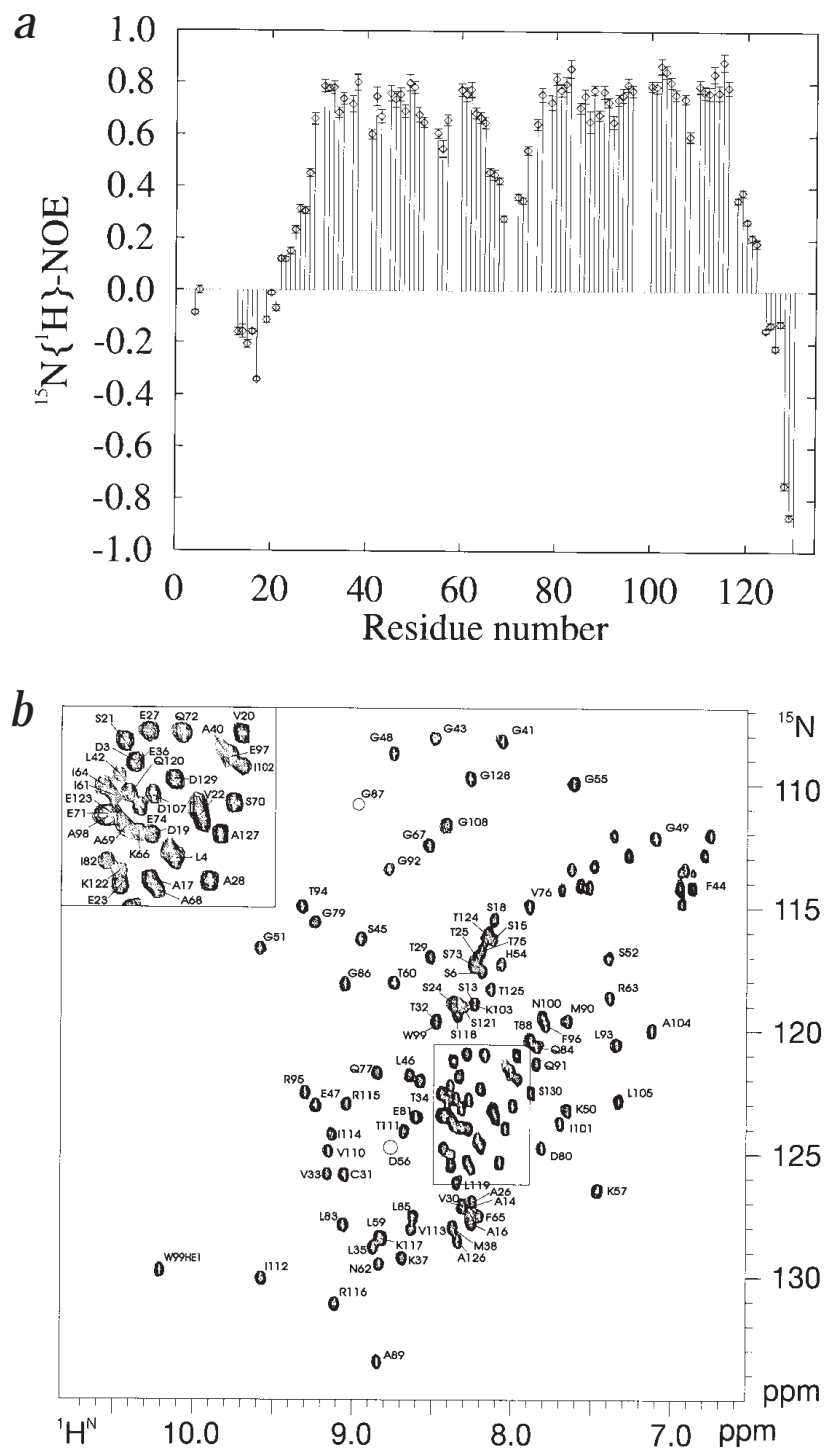

Fig. 1 a, Steady-state heteronuclear ${ }^{15} \mathrm{~N}\{\mathrm{H}\} \mathrm{NOE}$ for the backbone amides of IL-16. Residues for which no results are shown correspond either to prolines or to residues for which the relaxation data could not be extracted. b, ${ }^{1} \mathrm{H}^{-15} \mathrm{~N}$ HSQC spectrum of human IL-16 ${ }^{1-130}$ at $\mathrm{pH} 7.4$, circles identify residues for which cross peaks were observed only at $\mathrm{pH} 6.5$.

functional domain of a 631 amino acid precursor protein ${ }^{15}$. The recombinant IL-16 expressed in Escherichia coli shows full Iymphocyte chemo-attractant activity. The exact size of the bioactive IL-16 protein has, however, been unclear because the proteolytic cleavage of the precursor protein by a CD $8^{+}$cell lysate yielded a $17,000 \mathrm{M}_{\mathrm{r}}$ (by gel migration) C-terminal fragment which best agreed with a naturally processed protein of 121 amino acid ${ }^{15,16}$. Also, the mechanism of secretion or proteolytic cleavage is still unexplained as no signal peptides for the transport into the endoplasmatic reticulum can be found in the sequence of the pro-IL-16 (ref. 15).

In order to determine the correct size of the putative secreted IL-16 protein we initially used two constructs of the IL-16 cDNA for over-expressing its $\mathrm{H}$ is-tagged proteins in 

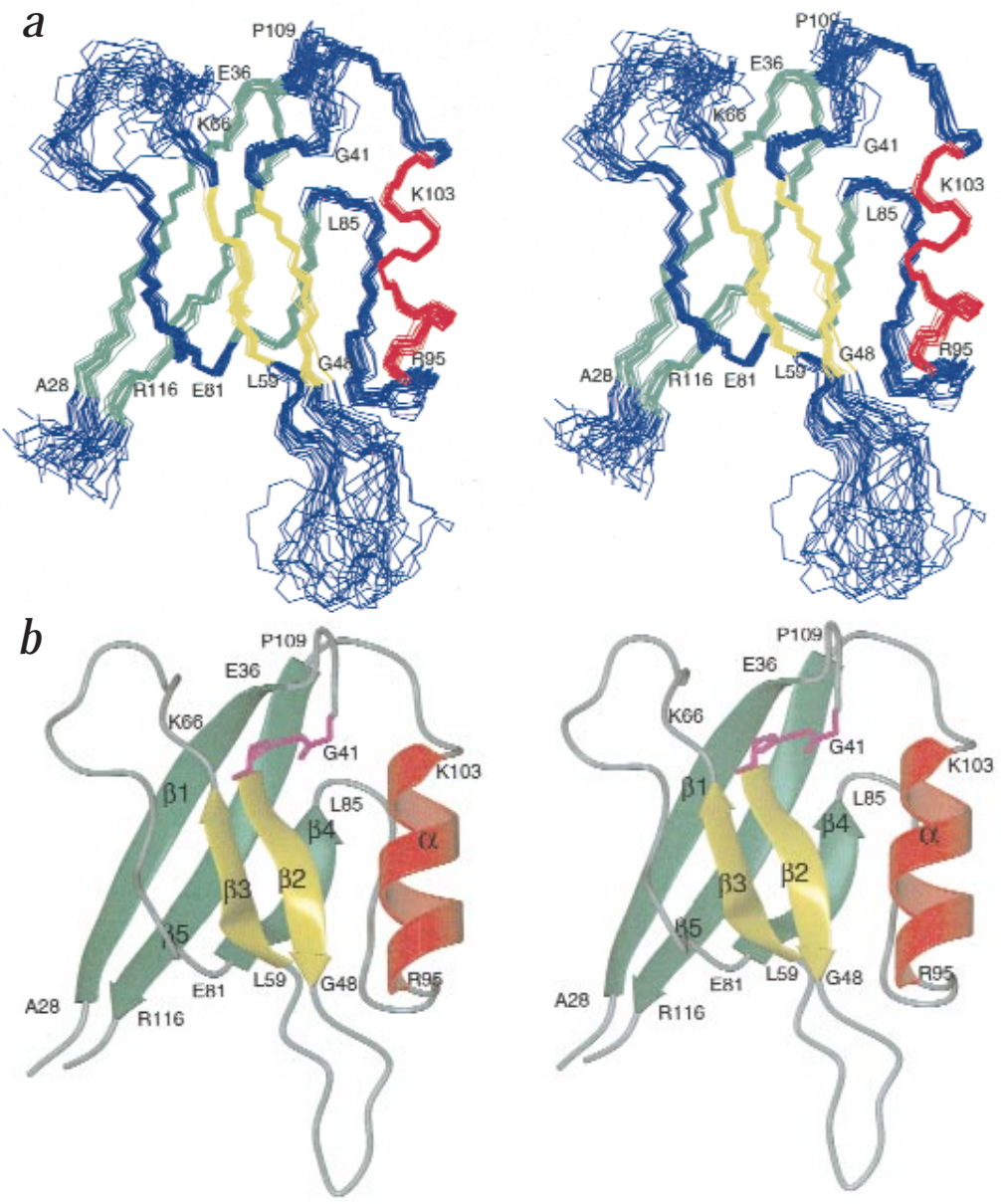

Fig. 2 a, Backbone overlay of NMR structures of human IL-16 (residues 28-118). For clarity, 20 structures were randomly chosen out of 70 . Helical residues are colored in red, $\beta$-sheets $\beta 1-\beta 5-\beta 3$ are in green; the Gly-Leu-Gly-Phecontaining $\beta$-sheet is shown in yellow. b, Ribbon representation of human IL-16 (residues 28-118) generated with $\mathrm{MOLMOL}^{32}$ from the mean structure $(\mathrm{SA})_{\mathrm{m}}$ which was obtained by a procedure described previously ${ }^{33}$. The GlyLeu-Gly-Phe residues are shown in pink.

NMR techniques using uniformly ${ }^{15} \mathrm{~N},{ }^{13} \mathrm{C} / 15 \mathrm{~N}$ labeled and selectively ${ }^{15} \mathrm{~N}-\mathrm{Ala},{ }^{15} \mathrm{~N}-\mathrm{Gly} / \mathrm{Ser},{ }^{15} \mathrm{~N}$ Leu labeled samples of IL-16-130. Fig. Ib shows the ${ }^{1 \mathrm{H}}-{ }^{15} \mathrm{~N}-\mathrm{HSQC}$ spectrum of IL-16.

The structure of IL-16 consists of a central upand-down $\beta$-sandwich (formed by $\beta$ - strands $\beta 1-\beta 5)$ which is adjacent to an $\alpha$-helix (Arg 95-Ala 104)(Fig. 2a,b). The $\mathrm{N}$-terminal $\beta$-strand ( $\beta 1$, Thr 29-Glu 36) makes an antiparallel $\beta$ sheet with the $\mathrm{C}$-terminal $\beta$-strand $\beta 5$ (Val 110 -Arg 116) and forms, together with the short $\beta$-strand $\beta 4$ (Ile 82 -Leu 85 ), one side of the $\beta$ sandwich. The second antiparallel $\beta$-sheet $\beta 2-\beta 3$, which is formed by the residues Phe 44-Glu 47 and Thr 60 -Ile 64 , contains a $\beta$-bulge in $\beta$-strand $\beta 3$ at residue Asn 62 . The two $\beta$-sheets that form the $\beta$-sandwich are packed against each other in a roughly parallel manner with a rotation of $39^{\circ}$ between the central axis of $\beta$-sheet $\beta 2-\beta 3$ and the central axis of $\beta$-sheet $\beta 1$ - $\beta 5$ (Fig. 2). The residues that form the core of IL-16 are all hydrophobic (Ile 61, Phe 44, Phe 96, Trp 99, Ile 112 , Ile 102, Leu 46). Poorly defined regions in

Escherichia coli: the first construct encoded the originally published protein of 130 amino acids (IL-161-130) ${ }^{14}$, the second an $\mathrm{N}$-terminally shortened protein of 121 amino acids (I L-169-130). N M R and proteolytic data unequivocally indicated that the Nterminal residues up to Glu 27 and the C-terminal residues starting from Lys 117 were disordered in solution. For example, these residues lacked long- and medium-range NOEs and showed negative or insignificant values of heteronuclear ${ }^{15} \mathrm{~N}$ N OEs for backbone amides (Fig. 1a); features characteristic of highly flexible residues ${ }^{17}$. We therefore constructed two shorter fragments, starting at Ser 24 to Glu 123 and from Ala 28 to Ser 130. Biochemical activity assays showed full chemo-attractant activity of these fragments (data not shown) and no change in structural properties of the 89-residuefolded part in the four constructs. We propose therefore that the shortest fully folded and cytokine active IL-16 has a size of 89 amino acids; this corresponds to residues Ala 28-Arg 116 of the original IL-16 130 amino acid sequence.

The structure of IL-16 was primarily determined from the 3D ${ }^{1} \mathrm{H}-{ }^{13} \mathrm{C}$ NOESY-HSQC spectra acquired on a double ${ }^{13} \mathrm{C} /{ }^{15} \mathrm{~N}$ labeled IL-16 (ref. 18 ). ${ }^{1 \mathrm{H}},{ }^{15} \mathrm{~N}$ and ${ }^{13} \mathrm{C}$ chemical shift assignments were obtained using standard triple resonance

Fig. 3. Sequence alignment of human IL-16, synaptic protein third domain (PSD-95) ${ }^{34}$, Discs-Large (DLG482-566)24, ZO1408-491, ZO293-176, p5567-153, NOS12-100 and syntrophin (bSYN2 $\left.{ }^{65-152}\right)^{22}$. The secondary structure of IL-16 is shown above the alignment. Residues involved in regular secondary structures in DSP-95 and DLG are marked with green ( $\beta$-strands) and blue ( $\alpha$-helices). Residues that determine specificity of PDZ domains for their target peptides are shown in gray. the structures are localized at loops Leu 37-Ala 40, Gly 51-Asn 55 and Gly 67 -Thr 75, for which very few long or medium NOEs were found, and none of these N OEs were to the core of
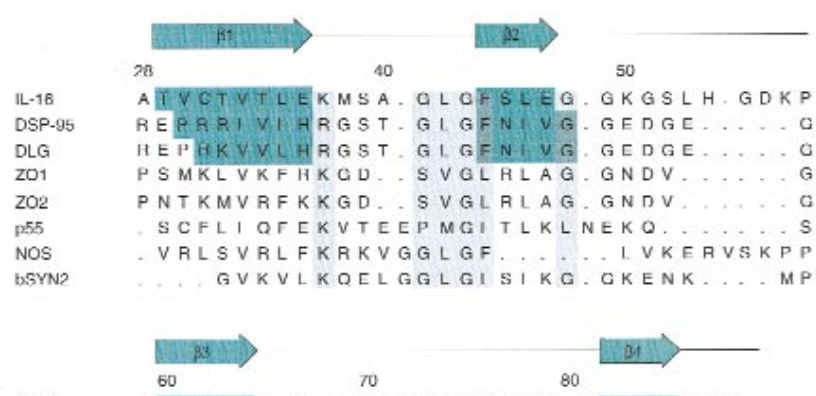

TIINRI FKGAASEQSETVQPGDFTIOLLGGTA

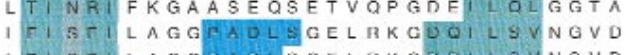
1 FI SFILACOAADLSCELBKODAI I SVNSVD I FVAGVLEDSPAAKEG. LEEGDQI LRVNNVD IFVAGI QEGTSAEOEG. LOEGDOI LKVNTQD CT VARILHGGMI HRQGSLHVGDEILEINGTN VI I SDL I RGGAAEQSGLI QAGDI I LAVNGHP I LISKIFKGLAAUOTOALYVGOAILSVNGAD

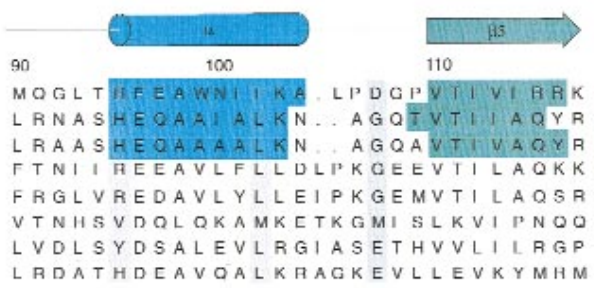




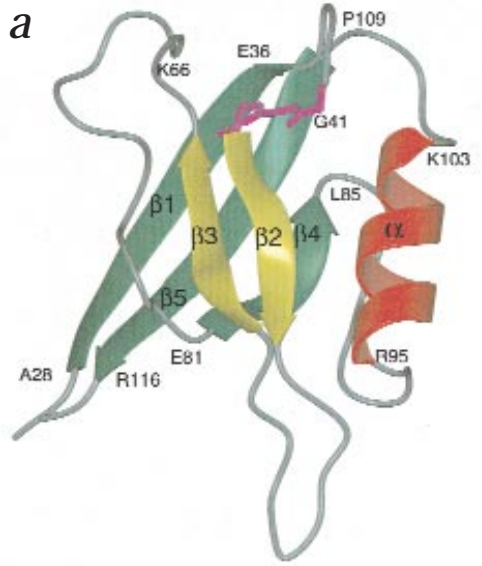

IL-16

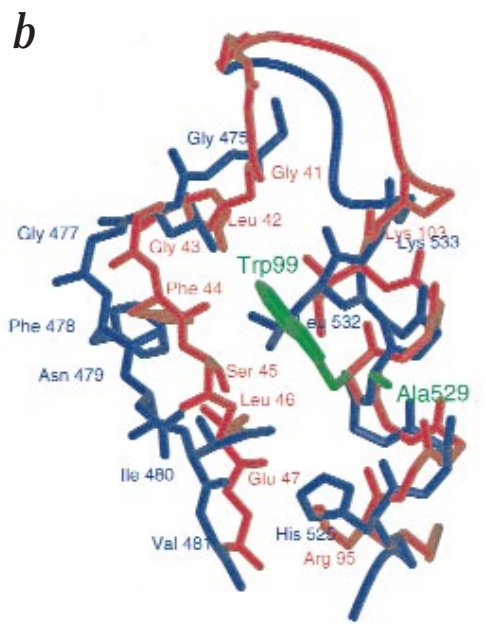

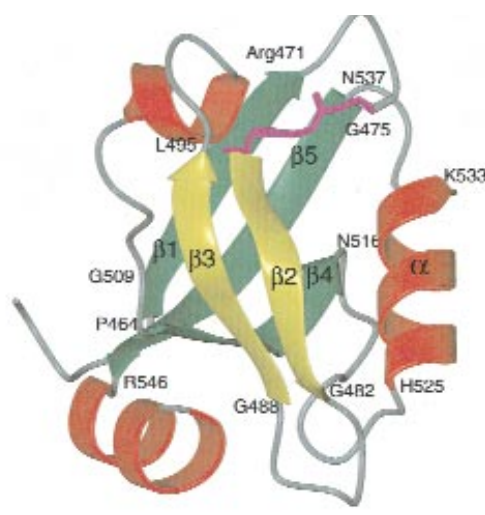

Fig. 4 a, Comparison of the overall topologies of IL-16 and Dlg_A. b, Conformation of the Gly-Leu-Gly-Phe cleft in human IL-16 (red). The side chain of Trp 99 is marked in green. Conformation of the side chain atoms for residues $41-46$ are also shown. Conformation of the GLGF site in human Dlg_A is in blue ${ }^{22}$. The side chain of Ala 529 is shown in green (this residue corresponds to Trp 99 in IL-16). the protein. Also, the TOCSY peaks for these fragments were stronger with noticeable reduction in the line widths compared to the peaks of residues in well-structured regions. These features were corroborated by ${ }^{15} \mathrm{~N}$ relaxation measurements, which showed low values of the heteronuclear ${ }^{15} \mathrm{~N}$ N OEs indicating increased flexibility of these fragments (Fig. 1a) ${ }^{17}$. Not all loops are flexible, however; the connecting loops between the $\alpha$-helix and $\beta$-stand $\beta 5, \beta$-strand $\beta 4$ and the $\alpha$ helix are well defined in the IL-16 structure (Figs 1a, 2a).

Center et al. suggested that homo-tetramerization of IL-16 may be required for its chemo-attractant bioactivity 6 . All four IL-16 constructs showed the presence of higher than monomeric species in solution. ${ }^{1 \mathrm{H}},{ }^{15} \mathrm{~N}$ and ${ }^{13} \mathrm{C}$ spectra exhibited line widths broader than those expected for monomeric proteins of $10,000-17,000 \mathrm{M}_{\mathrm{r}}$ at concentrations between $0.2-1.5 \mathrm{mM}$. Oligomerization properties of IL-16 were therefore studied with NMR using an IL-16 sample prepared by mixing $1: 1$ a ${ }^{13} \mathrm{C} /{ }^{15} \mathrm{~N} /{ }^{1} \mathrm{H}$ labeled $\mathrm{IL}-16$ with an unlabeled $\left({ }^{12} \mathrm{C} /{ }^{14} \mathrm{~N} /{ }^{11} \mathrm{H}\right)$ protein. With this sample, it should bepossible to determine intermolecular NOE interactions provided that defined oligomers are present in solution ${ }^{19}$. No intermolecular N OEs could be detected for IL-16 in the N M R spectra, indicating that the increase of N M R line widths is due to non-specific aggregation of the protein. This conclusion was corroborated with light scattering, size exclusion column and ultra centrifugation experiments which showed that at lower concentrations $(0.1 \mu \mathrm{M})$ IL-16 predominantly formed monomers with a high degree of non-specific aggregation at increasing concentrations (data not shown). Because of the full bioactivity of our recombinant IL-16, our experiments suggest that formation of homo-tetrameric protein is not required for the chemo-attractant function of IL-16.

Amino acid sequence alignments of IL-16 showed no significant homologies to other interleukins or any other member of the chemokine family. A search for structure similarities to the known protein folds with the program WHATIF ${ }^{20}$ revealed that the three-dimensional structure of IL-16 is similar to that of intracellular protein modules called PDZ domains. The name derives from three proteins that contain repeats of this domain: mammalian postsynaptic density protein $95 \mathrm{kD}$ (PSD-95); D rosphilia disc large tumor suppressor (DIgA); and the mammalian tight junction protein ZO1. IL-16 has low similarities to the PDZ domains of the presynaptic density protein 95 (31\% similarity) and the tight junction protein ZO-1 (34\% similarity) ${ }^{15}$ (Fig. 3). PDZ domains are intracellular protein modules that mediate clustering of ion channels, receptors and other membrane proteins and connect them to their appropriate signal transduction complexes ${ }^{21}$. PDZ domains are identified by the presence of a conserved Gly-LeuGly-Phe sequence that is responsible for binding of defined peptide consensus sequences. For example, PDZ domains were found to bind the $\mathrm{C}$-termini of several membrane proteins that possess a consensus sequence ( $\mathrm{Ser} / \mathrm{Thr}) \mathrm{XaaVal}(\mathrm{COOH})^{22}$. IL-16 sequence also contains the Gly-Leu-Gly-Phe motif. The 


\section{Table 1 Structure statistics of interleukin 16}

\begin{tabular}{|c|c|}
\hline \multicolumn{2}{|l|}{ Restraints for structure calculations } \\
\hline Total restraints used & 1,276 \\
\hline Total NOE restraints & 1,184 \\
\hline Intraresidue & 229 \\
\hline Sequential & 342 \\
\hline Medium range & 183 \\
\hline Long range & 416 \\
\hline Hydrogen bond restraints & 14 \\
\hline Statistic for structure calculations & $\langle S A>$ \\
\hline \multicolumn{2}{|l|}{ R.m.s.d. from idealized covalent geometry } \\
\hline Bonds $(\AA)$ & $0.0034 \pm 0.0003$ \\
\hline Bond angles $\left({ }^{\circ}\right)$ & $0.61 \pm 0.04$ \\
\hline Improper torsions $\left({ }^{\circ}\right)$ & $0.39 \pm 0.06$ \\
\hline \multicolumn{2}{|l|}{ R.m.s.d. from experimental constraints ${ }^{2}$} \\
\hline Distances $(\AA)$ & $0.070 \AA \pm 0.005$ \\
\hline \multicolumn{2}{|l|}{ Final energies ( $\left.\mathrm{kcal} \mathrm{mol}^{-1}\right)$} \\
\hline $\mathrm{E}_{\text {total }}$ & $491 \pm 22$ \\
\hline $\mathrm{E}_{\mathrm{bonds}}$ & $25 \pm 2$ \\
\hline$E_{\text {angles }}$ & $215 \pm 7$ \\
\hline$E_{\text {impropers }}$ & $29 \pm 3$ \\
\hline$E_{v d W}$ & $39 \pm 8$ \\
\hline$E_{\mathrm{NOE}}$ & $165 \pm 20$ \\
\hline Coordinate precision ${ }^{3}(\AA)$ & $\langle\mathrm{SA}>$ versus $\langle\overline{\mathrm{SA}}>$ \\
\hline \multicolumn{2}{|l|}{ R.m.s.d. of backbone atoms $\left(\mathrm{N}, \mathrm{C} \alpha, \mathrm{C}^{\prime}\right)$} \\
\hline excluding residues 1-27 38-40 51-55 67-75 117-130 & $0.60 \AA \pm 0.13$ \\
\hline \multicolumn{2}{|l|}{ R.m.s.d. of all heavy } \\
\hline excluding residues 1-27 37-40 51-55 67-75 117-130 & $1.35 \AA \pm 0.19$ \\
\hline
\end{tabular}

${ }^{1}<\mathrm{SA}>$ refers to the ensemble of the 70 structures. Force constants used to calculate energy terms are the same as in ${ }^{33}$

${ }^{2}$ No distance restraint in any of the structures included in the ensemble was violated by more than $0.4 \AA$.

${ }^{3}$ R.m.s.d. between the ensemble of structures $\angle \mathrm{SA}>$ and the average structure of the ensemble $\overline{\mathrm{SA}}>$

comparison of our structure of IL-16 with the X-ray structure of the DIg_A PDZ3 domain ${ }^{23}$ showed high similarities for both protein folds (Fig. 4a). The $\alpha$-helix and five $\beta$-sheets in thetwo proteins are at similar positions in the amino acid sequence relative to the Gly-Leu-Gly-Phe motif (Fig. 3). The IL-16 structure does not contain a short $\alpha$-helix between $\beta$-strand $\beta 3$ and $\beta$-strand $\beta 4$ and an $\alpha$-helix at the $C$-terminus, which are present in Dlg_A PDZ3. The pair-wise r.s.m.d. between the well-defined regions of IL-16 and the DIg A PDZ3 domain (excluding loops and additional helices in DIg A PDZ3) is $1.9 \AA$. The carboxylate binding loop Gly-Leu-Gly-Phe is located in both proteins directly before the second $\beta$-sheet, with the phenylalanine participating in this $\beta$-sheet; also, the Gly-Leu-Gly-Phe loop shows a high degree of similarity in $\phi$ and $\psi$ angles between the two structures, especially for the last two residues of this motif. The IL-16 fold would thus represent a single module extracellular PDZ domain protein.

The binding properties of IL-16 towards the PDZ-like binding peptides were studied with NM R and fluorescence spectroscopies. Six peptide sequences were chosen that comprised the most common peptide sequences shown to bind to PDZ domains ${ }^{22}$. O ne of these PDZ consensus sequence peptides, KNKKKKDETEV $(\mathrm{COOH})$, is often found at the C-terminus of viral proteins and was therefore included as a physiologically relevant binding partner because it may bind to IL-16 and thus explain the role of IL-16 as a CD $8^{+} T$ cell derived antiviral factor. NMR measurements followed the procedure called
'SAR by NMR' (ref. 24) and consisted of monitoring changes in chemical shifts and line widths of the backbone amide resonances of a uniformly ${ }^{15} \mathrm{~N}$-label ed IL- 16 sample in a series of ${ }^{1} \mathrm{H}-{ }^{15} \mathrm{~N}$ HSQC spectra as a function of peptide concentration. No changes in chemical shifts or line widths were observed during the titration, indicating that IL-16 does not bind these typical PDZ-binding peptides. The same results were obtained after subjecting the I L-16 peptide mixtures to the $\mathrm{GdmCl}$ denaturing conditions and subsequent refolding. Binding was also studied at lower protein concentrations with fluorescence spectroscopy by monitoring the fluorescence maximum of Trp 99 which is located in the Gly-Leu-Gly-Phe pocket. The absorption maximum of Trp 99 at $352 \mathrm{~nm}$ showed no shift even at a two-fold excess of any of the peptides. All these experiments show that IL16 does not have the usual peptide binding properties of a typical PDZ domain. In the IL-16 structure, the entry of a target peptide into the GLGF cleft is blocked (Fig. 4b); the IL-16 Gly-Leu-Gly-Phe cleft is much smaller than that found in structures of PDZdomains (the Gly-Leu-Gly-Phe fragment is moved by $\sim 4 \AA$ towards the $\alpha$-helix in IL-16 compared to Dlg A) and, in its center, filled with the bulky Trp 99 side chain (Fig. 4b).

\section{Methods}

Sample preparation. The human IL-16 was overexpressed as a fusion protein using a $\mathrm{pET} 16 \mathrm{~b}$ vector transformed in the E. coli strain BL21(DE3) (Novagen). The uniformly ${ }^{13} \mathrm{C} /{ }^{15} \mathrm{~N}$ and ${ }^{15} \mathrm{~N}$ - labeled protein samples were prepared by growing the bacteria in minimal media containing ${ }^{15} \mathrm{NH}_{4} \mathrm{Cl}\left(1 \mathrm{~g} \mathrm{l}^{-1}\right)$ either with or without ${ }^{13} \mathrm{C}_{6}$-glucose $\left(1 \mathrm{~g} \mathrm{l}^{-1}\right)$. For the selective labeled samples ${ }^{15} \mathrm{~N}-\mathrm{Gly} / 15 \mathrm{~N}-\mathrm{Ser}\left(1 \mathrm{~g} \mathrm{l}^{-1}\right),{ }^{15} \mathrm{~N}-\mathrm{Ala}\left(800 \mathrm{mg} \mathrm{ml}^{-1}\right)$ and ${ }^{15} \mathrm{~N}-$ Leu $(300 \mathrm{mg}$ $\mathrm{ml}^{-1}$ ) the minimal medium consisted of the isotopically enriched amino acid and all other unenriched amino acids. The protein was then affinity-purified on a Ni-NTA (Qiagen) column. The His-tag was removed from the unlabeled and ${ }^{15} \mathrm{~N}$ labeled samples with Factor Xa (Biolabs) and the proteins purified by anion exchange chromatography with Sepharose Q (20 mM imidazol buffer, $\mathrm{pH}$ 6.5). All samples were exchanged into PBS buffer ( $\mathrm{pH}$ 7.4) and concentrated with Centricon 3 (Amicon). Samples for NMR typically contained 1-2 mM protein. For recording spectra in $\mathrm{D}_{2} \mathrm{O}$, the samples were dissolved in $100 \% \mathrm{D}_{2} \mathrm{O}$. The $1: 1$ mixed labeled sample was prepared by combining equimolar amounts of ${ }^{13} \mathrm{C} /{ }^{15} \mathrm{~N} /{ }^{1} \mathrm{H}$ and ${ }^{12} \mathrm{C} /{ }^{14} \mathrm{~N} /{ }^{1} \mathrm{H}$ protein, denaturing the sample with $6 \mathrm{M} \mathrm{GdmCl}$ in the presence of DTT $(6 \mathrm{mM})$ and refolding by dialysis against PBS buffer (pH 7.4)

NMR spectroscopy. All NMR spectra were acquired at $17^{\circ} \mathrm{C}$ and $27^{\circ} \mathrm{C}$ on Bruker AMX500, DRX600 and DMX750 NMR spectrometers. Backbone sequential resonances were assigned using 3D HNCA, HN(CO)CA, HNCO and HN(CA)CO experiments ${ }^{18}$. The side chain resonances were assigned using 3D ${ }^{15} \mathrm{~N}$-TOCSY-HSQC and 3D HCCH-TOCSY experiments (employing mixing times of $19 \mathrm{~ms}$ and $8 \mathrm{~ms}$ for the HCCH-TOCSY). Stereospecific assignments were obtained from a combination of HNHB, DQF-COSY, short mixing time NOESY, 2D ${ }^{1 H^{N}-15} \mathrm{~N}-\{13 \mathrm{C}\}$ difference HSQC, 3D HN(CO)C and 2D ${ }^{13} \mathrm{C}^{1}-\left\{{ }^{3} \mathrm{C} \gamma\right.$ \{aromatics $\left.\}\right\}$ spin- echo difference and $2 \mathrm{D}{ }^{15} \mathrm{~N}$ $\left\{{ }^{3} \mathrm{C} \gamma\right.$ aromatics $\left.\}\right\}$ spin-echo difference ${ }^{1} \mathrm{H}^{\mathrm{N}}-15 \mathrm{~N}$ HSQC experiments ${ }^{25,26} . \chi 1$ angles in valine, isoleucine, and threonine residues 
were determined by $2 \mathrm{D}\left\{{ }^{15} \mathrm{~N}\right\}$ spin-echo difference CT-HSQC and 2D long-range ${ }^{13} \mathrm{C}-{ }^{13} \mathrm{C}$ correlation experiments ${ }^{27}$. The state of oligomerization was investigated with a $\left\{{ }^{13} \mathrm{C},{ }^{15} \mathrm{~N}\right\}$ double-half-filtered NOESY experiment utilizing WURST inversion pulses for optimal suppression of signals from ${ }^{13} \mathrm{C}$ labeled molecules ${ }^{19}$.

Structure calculations. Structures were calculated using a simulated annealing protocol implemented in the program X-PLOR ${ }^{28}$. Secondary structure elements were identified by analysis of the chemical shift index and NOE cross peak pattern ${ }^{29,30}$. Distance constraints were collected from $3 \mathrm{D}{ }^{15} \mathrm{~N}$ - and ${ }^{13} \mathrm{C}$-edited NOESY spectra and $2 \mathrm{D}{ }^{1} \mathrm{H}-\mathrm{NOESY}$ spectra and classified according to the peak intensities as very strong (2.3-2.6 $\AA$ ), strong (2.7-3.1 $\AA$ ), medium (3.1-3.5 $\AA$ ), weak-medium (3.6-4.2 $\AA$ ), weak (4.2-5.0 $\AA$ ). All protons were explicitly defined in the structure calculations; in some cases, however, additional terms were added to the upper bounds that correspond to the pseudoatom correction introduced by Wüthrich ${ }^{30}$. A total of $1,184^{1} \mathrm{H}-1 \mathrm{H}$ distances and $68 \phi$ torsion angle constraints derived from $\mathrm{HNHA}$ and $\mathrm{HN}(\mathrm{CO}) \mathrm{C}$ experiment were used for initial structure calculations. At the final stage three $\varphi$ angles for the trans-peptide bond of the X-Pro residues, together with the $21 \chi 1$ restraints were added. Stereospecific assignments could be obtained for 21 of the 62 prochiral centers of methylene and the Val, Leu isopropyl groups of the 89 residue structured IL-16. The statistics for the final structures is shown in Table 1.

Peptide titration. Peptide titration experiments were performed using a uniformly ${ }^{15} \mathrm{~N}$-labeled sample at the protein concentration of $\sim 0.2 \mathrm{mM}$ by recording ${ }^{1} \mathrm{H}-15 \mathrm{~N} \mathrm{HSQC}$ spectra. The peptide stock solution each contained $20 \mathrm{mM}$ of a peptide dissolved in the IL-16 buffer. The following PDZ peptides were synthesized and tested ${ }^{31}$ : KNKDKNQESDI, KNKKKKKEYFF, KQSSV, KNKKKKDETEV, KNKDKNQEFYA, YDSLV. Titration was carried out in ten steps by adding $0.04 \mathrm{mM}$ of a peptide, up to its final con-

1. Center, D. M. \& Cruikshank, W. W. Modulation of lymphocyte migration by human Iymphokines (identification and characterization). J. Immunol. 128 2563-2568 (1982)

2. Cruikshank, W. W. \& Center, D. M. Modulation of lymphocyte migration by human lymphokines (purification). J. Immunol. 128, 2569-2574 (1982).

3. Baier, M., Werner, A., Bannert, N., Metzner, K. \& Kurth, R. HIV suppression by interleukin-16. Nature 378,-563 (1995)

4. Rumsaeng, V., Cruikshank, W. W. \& Foster, B. Human mast-cells produce the CD4(+) T-lymphocyte chemoattractant factor, IL-16. J. Immunol. 159, 2904-2910 (1997).

5. Cruikshank, W. W., Greenstein, J. L., Theodore, A. C. \& Center, D. M. Lymphocyte chemoattractant factor induces CD4-dependent intracytoplasmic signaling in Iymphocytes. J. Immunol. 146, 2928-2934 (1991)

6. Center, D. M., Kornfeld, H. \& Cruikshank, W. W. Interleukin 16 and its function as a CD4 ligand. Immunol. Today 17, 476-481 (1996)

7. Baier, M. \& Kurth, R. Fighting HIV-1 with IL-16. Nature Med. 3, 605-606 (1997)

8. Bazan, J. F. \& Schall, T. J. Interleukin-16 or not? Nature 381, 29-30 (1996).

9. Mackewicz, C. E., Levy, J. A., Cruikshank, W. W., Kornfeld, H. \& Center, D. M. Role of IL-16 in HIV replication. Nature 383, 488-489 (1996).

10. Levy, J. A., Mackewicz, C. E. \& Barker, E. Controlling HIV pathogenesis: the role of the noncytotoxic anti-HIV response of CD8+ T cells. Immunol. Today 17 217-224 (1996)

11. Zhou, P., Goldstein, S., Devadas, K., Tewari, D. \& Notkins, A. L. Human CD4+ cells transfected with IL-16 CDNA are resistant to HIV-1 infection: Inhibition of mRNA expression. Nature Med. 3, 659-664 (1997)

12. Viglianti, G. A. et al. IL-16 anti-HIV-1 therapy. Nature Med. 3, 938 (1998)

13. Maciaszek, J. W. et al. IL-16 represses HIV-1 promoter activity. J. Immunol. 158, 5-8 (1997).

14. Cruikshank, W. W. et al. Molecular and functional analysis of a lymphocyte chemoattractant factor: Association of biologic function with CD4 expression. Proc. Natl. Acad. Sci. USA 91, 5109-5113 (1994).

15. Baier, M., Bannert, N., Werner, A., Lang, K. \& Kurth, R. Molecular cloning sequence, expression, and processing of the interleukin 16 precursor. Proc Natl. Acad. Sci.USA 94, 5273-5277 (1997).

16. Zhang, Y. et al. Processing and activation of pro-interleukin-16 by caspase-3. J. Biol. Chem. 273, 1144-1149 (1998).

17. Farrow, N. A. et al. Backbone dynamics of a free and a phosphopeptidecomplexed Src homology 2 domain studied by ${ }^{15} \mathrm{~N}$ NMR relaxation. Biochemistry 33, 5984-6003 (1994).

18. Edison, A. S., Abildgaard, F., Westler, W. M., Mooberry, E. S. \& Markley, J. L. Practical introduction to theory and implementation of multinuclear, centration of $0.4 \mathrm{mM}$. Additionally, the binding peptide properties of IL-16 were checked after unfolding IL-16 with $6 \mathrm{M} \mathrm{GdmCl}$. Refolding of ${ }^{15} \mathrm{~N}$ labeled IL-16 was carried out in the presence of the peptide (PBS buffer, $\mathrm{pH}$ 7.4). ${ }^{1} \mathrm{H}-{ }^{15} \mathrm{~N}$ HSQC spectra was recorded and compared with the spectrum of the sample before denaturation. No changes in chemical shifts or line widths were observed in the HSQC spectra before and after the denaturationrefolding experiment.

Coordinates. The Brookhaven Protein Data Bank accession number for the coordinates is li16.

\section{Acknow ledgments}

We thank R. Engh for stimulating discussions, F. Hesse for protein purification, H. Burtscher for cloning and expression, H. Popp for fermentation, M. Wozny for mass analysis and R. Rudolf for analytical ultracentrifugation. M. Z. is a recipient of the graduate scholarship from Verband der Chemischen Industrie.

Peter Mühlhahnn, Markus Zweckstetter ${ }^{1}$, Julia Georgescu$^{1}$, Cornelia Ciosto ${ }^{1}$, Christian Renner ${ }^{1}$, Martin Lanzendörfer'2, Kurt Lang2, Dorothee Ambrosius $^{2}$, Michael Baier ${ }^{3}$, Reinhard Kurth ${ }^{3}$ and Tad A. Holak ${ }^{3}$

${ }^{1}$ M ax Planck Institute for Biochemistry, Am Klopferspitz 18a, D-82152 Martinsried, F.R.G., Germany. ${ }^{2}$ Boehringer Mannheim Biotechnology Research Center, Nonnenwald 2, D-82372 Penzberg, F.R.G., Germany. ${ }^{3}$ Paul Ehrlich Institute, Paul-Ehrlich-Str. 51-59, D-63225 Langen, F.R.G., Germany.

Correspondence should be addressed to T.A.H.email: holak@biochem.mpg.de

Received 25 March; accepted 9 J une 1998.

multidimensional nuclear magnetic resonance experiments. Meth. Enz. 239, 3-79 (1994).

19. Zwahlen, C. et al. Methods for measurement of intermolecular NOEs by multinuclear NMR spectroscopy: Application to a bacteriophage Npeptide/box B RNA complex. J. Am. Chem. Soc. 119, 6711-6721 (1997).

20. Vriend, G. WHAT IF: a molecular modeling and drug design program. J. Mol. Graph. 8, 52-56 (1990).

21. Ponting, C. P. \& Phillips, C. DHR domains in syntrophins, neuronal NO synthases and other intracellular proteins Trends Biochem. Sci. 20, 102-103 (1995).

22. Songyang, $Z$. et al. Recognition of unique carboxyl-terminal motifs by distinct PDZ domains. Science 275, 73-77 (1997)

23. Cabral, J. H., Petosa, C. \& Sutcliffe, M. J. Crystal structure of a PDZ domain. Nature 382, 649-652 (1996).

24. Shuker, S. B., Hajduk, P. J., Meadows, R. P. \& Fesik, S. W. Discovering highaffinity ligands for proteins: SAR by NMR. Science 274, 1531-1534 (1996).

25. Hu, J. S. \& Bax, A. 01 angle information from a simple 2-dimensional NMR experiment that identifies trans ${ }^{3} \int_{\mathrm{NC}}$ couplings in isotopically enriched proteins. J. Biomol. NM R 9, 323-328 (1997)

26. Hu, J. S. \& Bax, A. Determination of . angles and 01 angles in proteins from ${ }^{13} \mathrm{C}$ ${ }^{13} \mathrm{C}$ three-bond J-couplings measured by 3-dimensional heteronuclear NMR How planar is the peptide bond. J. Am. Chem. Soc. 119, 6360-6368 (1997).

27. Vuister, G. W. et al. Measurement of homo- and heteronuclear J-couplings from quantitative J correlation. Meth. Enz. 239, 79-105 (1994)

28. Brünger, A.T. X-PLOR, Version 3.1: System for X-ray Crystallography and NMR Yale Univ. Press, New Haven and London, (1992).

29. Wishart, D. S., Sykes, B. D., \& Richards, F. M. Relationship between nuclear magnetic resonance chemical shift and protein secondary structure. J. Mol. Biol. 222, 311-333 (1991)

30. K Wüthrich, NMR of Proteins and Nucleic Acids (Wiley, New York, 1986).

31. Schultz, J. et al. Specific interactions between the syntrophin PDZ domain and voltage gated sodium channels. Nature Struct. Biol. 5, 19-24 (1998)

32. Koradi, R., Billeter, M. \& Wüthrich, K. MOLMOL: a program for display and analysis of macromolecular structures. J. Mol. Graph. 14, 51-55 (1996).

33. Holak, T. A., Gondol, D., Otlewski, J. \& Wilusz, T. Determination of the complete 3-dimensional structure of the trypsin-inhibitor from squash seeds in aqueous-solution by nuclear magnetic-resonance and a combination of distance geometry and dynamical simulated annealing. J. Mol. Biol. 210, 635-648 (1989).

34. Doyle, D. A. et al. Crystal structures of a complexed and peptide-free membrane protein-binding domain: molecular basis of peptide recognition by PDZ. Cell 85, 1067-1076 (1996). 